Sādhanā Vol. 29, Part 6, December 2004, pp. 641-667. ( ) Printed in India

\title{
Numerical study of effect of oxygen fraction on local entropy generation in a methane-air burner
}

\author{
HUSEYIN YAPICI, GAMZE BASTURK, NESRIN KAYATAS and \\ BILGE ALBAYRAK
}

Erciyes Üniversitesi Mühendislik Fakültesi, 38039 Kayseri, Turkey

e-mail: yapici@erciyes.edu.tr

MS received 11 March 2004; revised 30 September 2004

\begin{abstract}
This study considers numerical simulation of the combustion of methane with air, including oxygen and nitrogen, in a burner and the numerical solution of local entropy generation rate due to high temperature and velocity gradients in the combustion chamber. The effects of equivalence ratio $(\phi)$ and oxygen percentage $(\gamma)$ on combustion and entropy generation rates are investigated for different $\phi$ (from 0.5 to 1.0 ) and $\gamma$ values (from 10 to $30 \%$ ). Combustion is simulated for the fuel mass flow rate resulting in the same heat transfer rate $(\dot{Q})$ to the combustion chamber in each case. Numerical calculation of combustion is performed individually for all cases with the use of the Fluent CFD code. Furthermore, a computer program has been developed to calculate the volumetric entropy generation rate and the other thermodynamic parameters numerically by using the results of the calculations performed with the FLUENT code. The predictions show that the increase of $\phi$ (or the decrease of $\lambda$ ) significantly reduces the reaction rate levels. Average temperature in the combustion chamber increases by about 70 and $35 \%$ with increase of $\gamma$ (from 10 to $30 \%$ ) and $\phi$ (from 0.5 to 1.0 ) respectively. With increase of $\gamma$ from 10 to $30 \%$, volumetric local entropy generation rate decreases by about 9 and $4 \%$ for $\phi=0.5$ and 1.0 respectively, while total entropy generation rate decreases exponentially and the merit numbers increase. The ratio of the rates useful energy transfer to irreversibility therefore improves as the oxygen percentage increases.
\end{abstract}

Keywords. Air-fuel combustion; local entropy generation; exergy; computational fluid dynamics.

\section{Introduction}

During combustion fossil and renewable fuels are converted into a different fuel and/or heat and/or electricity. Combustion of fuel involves converting the chemical energy contained in the fuel into chemical energy contained in the gaseous products and sensible energy of the produced gas. Burners are used widely in a variety of industrial combustion systems, where there is need to ensure efficient combustion conditions which is associated with good 
fluid mixing and long reaction times. In many combustion devices, both air and fuel are in the gaseous phase and coaxial geometry is commonly used to merge the two streams. The principal objectives of research work in the area of combustion are to improve the combustion process in order to achieve higher combustion efficiency with a uniform exit temperature and allowable linear wall temperature distribution and to reduce combustion-generated polluting gases. However, the chemical and physical processes involved in combusting flows and their interactions are extremely complex and are often not well understood.

Combustion phenomena are a complex mixture of fluid dynamics and chemistry. Therefore, CFD (computational fluid dynamics) can serve as a powerful tool, and can be used to perform low-cost parametric studies involving critical burner design parameters. The CFD-codes solve the governing mass, momentum and energy equations in order to calculate the velocity, pressure and temperature fields. The main advantage of this computational approach is in its potential for reducing the extent and number of experiments required to describe such types of flow. In the near future, it may well be that computer simulation of combustion system will become a standard design tool.

On the other hand, the thermodynamic performance of a device or process can be assessed through the measure of the irreversibility generated. According to the first law of thermodynamics, energy can never be lost. Therefore it is justifiable to state that energy conversion processes do not have energy losses, except for losses from the process system into the environment. However, the second law of thermodynamics should also be considered for evaluating the sources of irreversibility in flow and thermal systems. Conserving useful energy depends on designing efficient thermodynamic heat-transfer processes. Energy conversion processes are accompanied by an irreversible increase in entropy, which leads to a decrease in exergy (available energy). Thus, even though energy is conserved, the quality of energy decreases because energy is converted into a different form of energy, from which less work can be obtained. Reduced entropy generation results in more efficient designs of energy systems. Therefore, in recent years, entropy minimization has become a topic of great interest in the thermo-fluid area. Bejan (1996a) focused on the different reasons behind entropy generation in applied thermal engineering where the generation of entropy destroys the available work (exergy) of a system. Therefore, it makes good engineering sense to focus on the irreversibility of heat transfer and fluid flow processes, and to try to understand the function of associated entropy generation mechanisms. Bejan (1996b) also conducted an extensive review on entropy generation minimization. The review traced the development and adoption of the method in several sectors of mainstream thermal engineering and science. Furthermore, many researchers have studied the entropy generation in various flow cases. Second-law analysis of heat transfer in swirling flow through a cylindrical duct was investigated by Mukherjee et al (1987), who calculated the rate of entropy generation. They also defined a merit function and discussed the influence of swirling on this function. Mahmud \& Fraser (2003) also investigated the second-law analysis in fundamental convective heat transfer problems and the thermodynamic analysis of flow and heat transfer inside channel with two parallel plates (Mahmud \& Fraser 2002). Sahin (1998, 1999, 2000, 2002), Yilbas et al (1999), Shuja et al (2001a), Demirel \& Kahraman (1999) and Abbassi et al (2003) performed many studies on second law analysis and the entropy generation due to the heat transfer and fluid friction in duct flows under various conditions. Shuja and coworkers analysed entropy generation in swirling jet impingement on an adiabatic wall (Shuja \& Yilbas 2001b; 2003) and an impinging jet (Shuja et al 2001b) for various flow conditions.

The present study considers the combustion of methane with air and the local entropy generation rate due to the high temperature and velocity gradients in combustion chamber 
of burner. In order to investigate the effect of oxygen percentage on the combustion and entropy generation rate, the combustion of methane with air is examined at various oxygen percentages in the air by using Fluent CFD code (Fluent Inc. 2003).

\section{Mathematical model}

\subsection{Burner geometry}

The main aim of this study is to estimate numerically the rate of local entropy generation in the combustion chamber of a burner. For this purpose, the combustion of methane $\left(\mathrm{CH}_{4}\right)$ with air in a burner was considered. The two-dimensional axisymmetric model and geometric configuration of the burner are shown in figure 1. As apparent from this figure, the methane and air inlets are coaxial and merge downstream. It is assumed that the burner wall is under ambient conditions and that the walls neighbouring the air and fuel inlets are isolated.

In order to estimate the effects of oxygen percentage in the air and equivalence ratio, defined in section $2 \cdot 2$, on below combustion and entropy generation rates, different (consecutive) oxygen percentages and equivalence ratios were studied. In this study, combustion is simulated for the fuel mass flow rate resulting in the same heat transfer rate $(\dot{Q})$ to the combustion chamber in the each case. Simulations performed with equal heat transfer rate approximation would facilitate comparison of the local entropy generation in the combustion chamber due to other geometries. Numerical calculation of the combustion was performed using the Fluent CFD code.

\subsection{Mathematical model}

The model used for the numerical calculations include:

- for turbulent flow, the RNG (renormalization group theory) $k-\varepsilon$ model (Yakhot \& Orszag 1986)

- for chemical species transport and reacting flow, the eddy-dissipation model with the diffusion energy source option

The assumptions made are as follows.

- the Flow is steady, two-dimensional axisymmetric, turbulent and compressible

- the Fuel-air mixture is assumed to behave as an ideal gas

- No-slip condition is assumed at the burner walls

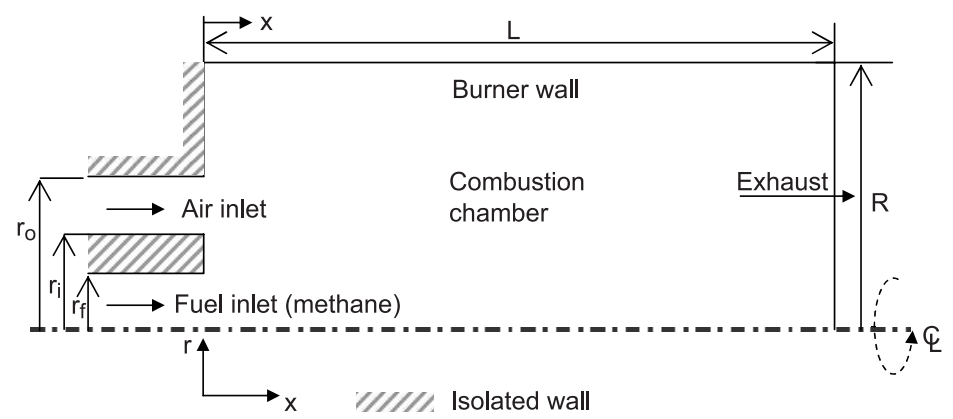

Figure 1. Coordinate system and two-dimensional axisymmetric model of the burner (dimensions are not to scale). 
2.2a Governing conservation equations: Governing mass, momentum and energy conservation equations for steady-state gas flow are given in tensor notation as follows.

Mass conservation equation (species transport equations) -

$$
\frac{\partial}{\partial x_{i}}\left(\rho u_{i} m_{i^{1}}\right)=-\frac{\partial}{\partial x_{i}} J_{i^{1}, i}+R_{i^{1}}
$$

$J_{i^{1}, i}$ (mass diffusion) is written for turbulent flows as follows:

$$
J_{i^{1}, i}=-\left(\rho D_{i^{1}, m}+\frac{\mu_{t}}{S c_{t}}\right) \frac{\partial m_{i^{i}}}{\partial x_{i}}
$$

where $D_{i^{1}, m}$ is the diffusion coefficient for species $i^{\prime}$ in the mixture and

$$
D_{i^{1}, m}=\left(1-X_{i^{1}}\right) / \sum_{j^{1}, j^{1} \neq i^{1}} X_{j^{1}} / D_{i^{1} j^{1}}
$$

$D_{i^{1} j^{1}}$ is the binary mass diffusion coefficient for species $i^{\prime}$ in species $j^{\prime}$.

An equation of this form is solved for $N-1$ species where $N$ is the total number of fluid phase chemical species present in the system.

The momentum conservation equation -

$$
\frac{\partial}{\partial x_{j}}\left(\rho u_{i} u_{j}\right)=-\frac{\partial P}{\partial x_{i}}+\frac{\partial \tau_{i j}}{\partial x_{j}}
$$

and

$$
\tau_{i j}=\left[\mu\left(\frac{\partial u_{i}}{\partial x_{j}}+\frac{\partial u_{j}}{\partial x_{i}}\right)\right]-\frac{2}{3} \mu \frac{\partial u_{l}}{\partial x_{l}} \delta_{i j} .
$$

The energy conservation equation -

$$
\frac{\partial}{\partial x_{i}}\left[u_{i}(\rho E+P)\right]=\frac{\partial}{\partial x_{i}}\left(\lambda_{e f f} \frac{\partial T}{\partial x_{i}}-\sum_{j^{1}} h_{j^{1}} J_{j^{1}}+u_{j}\left(\tau_{i j}\right)_{e f f}\right)+S_{h}
$$

where $J_{j^{1}}$ is the diffusion flux of species $j^{1}, S_{h}$ includes heat of chemical reaction and any other volumetric heat sources,

$$
E=h-\frac{P}{\rho}+\frac{u_{i}^{2}}{2},
$$

where $h$ is defined for ideal gases as:

$$
h=\sum_{j^{1}} m_{j^{1}} h_{j^{1}},
$$

where

$$
h_{j^{1}}=\int_{T_{\mathrm{ref}}}^{T} C_{p, j^{1}} \mathrm{~d} T
$$


$\lambda_{\text {eff }}$ is the effective conductivity and for the RNG $k-\varepsilon$ model,

$$
\lambda_{\mathrm{eff}}=\alpha \cdot C_{p} \cdot \mu_{\mathrm{eff}},
$$

where $\alpha$, the inverse effective Prandtl number, is computed using the following formula derived analytically by the RNG theory:

$$
\left|\frac{\alpha-1.3929}{\alpha_{0}-1 \cdot 3929}\right|^{0.6321} \cdot\left|\frac{\alpha+2 \cdot 3929}{\alpha_{0}+2 \cdot 3929}\right|^{0.3679}=\frac{\mu}{\mu_{\text {eff }}}
$$

where

$$
\alpha_{0}=\lambda / \mu C_{P}
$$

Two additional equations for the RNG $k-\varepsilon$ turbulence model - The turbulence kinetic energy, $k$, and the dissipation rate, $\varepsilon$, are determined using the following transport equations, respectively:

$$
\begin{aligned}
\frac{\partial}{\partial x_{i}}\left(\rho u_{i} k\right) & =\frac{\partial}{\partial x_{i}}\left(\alpha_{k} \mu_{e f f} \frac{\partial k}{\partial x_{i}}\right)+G_{k}-\rho \varepsilon, \\
\frac{\partial}{\partial x_{i}}\left(\rho u_{i} \varepsilon\right) & =\frac{\partial}{\partial x_{i}}\left(\alpha_{\varepsilon} \mu_{e f f} \frac{\partial \varepsilon}{\partial x_{i}}\right)+\frac{\varepsilon}{k}\left(C_{1 \varepsilon} G_{k}-C_{2 \varepsilon} \rho \varepsilon\right)-\chi
\end{aligned}
$$

where $\alpha_{k}$ and $\alpha_{\varepsilon}$ the inverse effective Prandtl numbers for $k$ and $\varepsilon$, respectively, are calculated from (3f) by using $\alpha_{0}=1$,

$$
\mu_{\mathrm{eff}}=\mu+\mu_{t}, \mu_{t}=\rho C_{\mu}\left(k^{2} / \varepsilon\right),
$$

$C_{\mu}, C_{1}$ and $C_{2 \varepsilon}$ are the model constants,

$$
G_{k}=\mu_{t} S^{2},
$$

and

$$
\chi=C_{\mu} \rho \frac{\eta^{3}\left(1-\left(\eta / \eta_{0}\right)\right)}{1+\beta \eta^{3}} \frac{\varepsilon^{2}}{k} .
$$

$S$ the modulus of the mean rate-of-strain tensor is defined as

$$
S=\left(2 S_{i j} S_{i j}\right)^{1 / 2} .
$$

$S_{i j}$ (the mean strain rate) is given by:

$$
\begin{aligned}
S_{i j} & =\frac{1}{2}\left(\frac{\partial u_{i}}{\partial x_{j}}+\frac{\partial u_{j}}{\partial x_{i}}\right), \\
\eta & =S \cdot(k / \varepsilon),
\end{aligned}
$$

$\eta_{0}=4 \cdot 38$, and $\beta=0 \cdot 012$. 
Thermal properties of the mixture - Fluid density is calculated using the ideal-gas law. Density, viscosity, specific heat and thermal conductivity of the mixture are calculated from the relevant properties of the species in the mixture according to the ideal-gas-mixing-law as follows:

$$
\begin{aligned}
\rho & =\left(P_{o p}+P\right) / \Re T \sum_{i^{1}}\left(m_{i^{1}} / M_{i^{1}}\right), \\
C_{p} & =\sum_{i^{1}} m_{i^{1}} C_{p, i^{1}}, \\
\lambda & =\sum_{i^{1}}\left[X_{i^{1}} \lambda_{i^{1}} /\left(\sum_{j^{1}} X_{j^{1}} \varphi_{i^{1}, j^{1}}\right)\right], \\
\mu & =\sum_{i^{1}}\left[X_{i^{1}} \mu_{i^{1}} /\left(\sum_{i^{1}} X_{i^{1}} \varphi_{i^{1} j^{1}}\right)\right],
\end{aligned}
$$

and

$$
\cdot \varphi_{i^{1} j^{1}}=\frac{\left[1+\left(\mu_{i^{1}} / \mu_{j^{1}}\right)^{1 / 2}\left(M_{j^{1}} / M_{i^{1}}\right)^{1 / 4}\right]^{2}}{\left[8\left(1+M_{i^{1}} / M_{j^{1}}\right)\right]^{1 / 2}} .
$$

Boundary conditions -

At the fuel inlet $\left(x=0\right.$ and $\left.0<r<r_{f}\right), u_{x}=U_{f}, u_{r}=0$, and $T=T_{\text {in }} \quad(6 \mathrm{a}-\mathrm{d})$

At the air inlet $\left(x=0\right.$ and $\left.r_{i}<r<r_{o}\right), u_{x}=U_{\text {air }}, u_{r}=0, T=T_{\text {in }}, \quad(6 \mathrm{e}-\mathrm{g})$

At the isolated walls $\left(x=0, r_{f}<r<r_{i}\right.$ and $\left.r_{o}<r<R\right), \partial T / \partial x=0$

At the burner wall $(r=R$, and $0<x \leq L)$,

$u_{r}=0$,

natural convection is assumed, i.e.

$$
q^{\prime \prime}(x)=-h_{\mathrm{amb}}\left[T(x, R)-T_{\mathrm{amb}}\right],
$$

and the no-slip condition is assumed, i.e.

$$
u_{x}=0 .
$$

Since the profiles of velocity and temperature are both symmetric with respect to the axis of the burner, the relevant boundary conditions at the symmetry axis $(r=0)$ are

$$
\partial \psi / \partial r=0
$$

where $\psi$ is any arbitrary variable.

At the outlet, $\partial \psi / \partial x=0$, All velocities are zero except the axial velocity. 
2.2b Combustion of fuel with air: The simplest description of combustion is that it is a process that converts the reactants available at the beginning of combustion into products at the end of the process. The most common combustion processes encountered in engineering are those which convert a hydrocarbon fuel (which might range from pure hydrogen to almost pure carbon $(\mathrm{C})$, e.g. coal) into carbon dioxide $\left(\mathrm{CO}_{2}\right)$ and water $\left(\mathrm{H}_{2} \mathrm{O}\right)$. They are usually exothermic (i.e. they release the chemical (or bond) energy contained in the fuels as thermal energy).

Reaction mechanism - In this study, the combustion of methane with oxygen is modelled with a two-step reaction mechanism $\left(N_{R}=2\right.$ and species number, $\left.N=5\right)$ where production and combustion of carbon monoxide (CO) is taken into account. In the first stage, methane is oxidized into carbon monoxide and water vapour and in the second, carbon monoxide oxidizes into carbon dioxide. The reaction mechanism takes place according to the constraints of chemistry, and is defined by:

$$
\begin{aligned}
& \mathrm{CH}_{4}+1 \cdot 5 \mathrm{O}_{2} \Rightarrow \mathrm{CO}+2 \mathrm{H}_{2} \mathrm{O} \quad(\text { step } 1),(\text { reaction } 1), \\
& \left.\mathrm{CO}+0 \cdot 5 \mathrm{O}_{2} \Rightarrow \mathrm{CO}_{2} \quad \text { (step 2), (reaction } 2\right)
\end{aligned}
$$

A lean mixture occurs when the quantity of air available for combustion is greater than the chemically correct quantity for complete oxidation of the fuel; this means that there is excess air available. The equation for combustion of a lean mixture of methane-air is

$$
\begin{aligned}
& \mathrm{CH}_{4}+\frac{2}{\phi}\left(\mathrm{O}_{2}+\frac{100-\gamma}{\gamma} \mathrm{N}_{2}\right) \\
& \Rightarrow \mathrm{CO}_{2}+2 \mathrm{H}_{2} \mathrm{O}+2\left(\frac{1-\phi}{\phi}\right) \mathrm{O}_{2}+\frac{2}{\phi} \frac{100-\gamma}{\gamma} \mathrm{N}_{2}, \text { for } 0<\phi \leq 1,
\end{aligned}
$$

divided by the actual air/fuel ratio, $A F R_{\text {act }}$, i.e.:

$$
\phi=\frac{A F R_{\text {sto }}}{A F R_{\text {act }}}
$$

where

$$
A F R_{\text {sto }}=2\left(M_{O 2}+(100-\gamma) / \gamma M_{N 2} / M_{f}\right),
$$

and

$$
A F R_{\mathrm{act}}=\dot{m}_{a i r} / \dot{m}_{f}
$$

The combustion reactions, $(7 a, b)$, give reaction enthalpy and the value of this enthalpy is the negative of the lower calorific value (LCV) of methane because it is based on gaseous water in the products. However, its value is taken to be a positive value for the flowing fluid because it is transferred into the flowing fluid inside the burner chamber during the combustion process. Therefore, the reaction energy released in the chemical reaction is added to the $S_{h}$ term in (3a) as the positive volumetric energy source.

The lower heating value, LHV, and LCV of the fuel can be calculated as

$$
\mathrm{LHV}=\sum H_{P}-\sum H_{R} \text { and } \mathrm{LCV}=-\mathrm{LHV},
$$

where $H_{P}$ and $H_{R}$ are the enthalpies of product and reactant species respectively. 
The fuel mass flow rate providing a desired heat transfer rate to the combustion chamber during the combustion process is calculated by

$$
\dot{m}_{f}=\dot{Q} \cdot M_{f} / \mathrm{LCV} .
$$

The eddy-dissipation model - In turbulent reacting flows, the Arrhenius reaction rate, the eddydissipation-model reaction rates given by $(9 \mathrm{~b}, \mathrm{c})$, or both, depending on the problem definition, are calculated. In this study, the reaction rates that appear as source terms in (1) (species transport equations) are computed by using the eddy-dissipation concept of Magnussen $\&$ Hjertager (1976). The source of chemical species $i^{1}$ due to reaction, $R_{i^{1}}$, is computed as the sum of the reaction sources over the $N_{R}$ reactions that the species may participate in:

$$
R_{i^{1}}=M_{i^{1}} \sum_{k=1}^{N_{R}} \widehat{R}_{i^{1}, k},
$$

where $\widehat{R}_{i^{1}, k}$ is the molar rate of creation/destruction of species $i^{1}$ in reaction $k$. The reaction rate, $R_{i^{1}, k}$, is controlled either by an Arrhenius kinetic rate expression or by the mixing of the turbulent eddies containing fluctuating concentrations of species.

The influence of turbulence on the reaction rate is taken into account by employing the Magnussen \& Hjertager model (1976). In the eddy-dissipation model, the rate of reaction $R_{i^{1}, k}$ is given by the smaller (i.e., limiting value) of the two expressions below:

$$
\begin{aligned}
R_{i^{1}, k} & =v_{i^{1}, k}^{1} M_{i^{1}} A \rho \frac{\varepsilon}{k} \frac{m_{R}}{v_{R, k}^{1} M_{R}}, \\
R_{i^{1}, k} & =v_{i^{1}, k}^{1} M_{i^{1}} A B \rho \frac{\varepsilon}{k} \frac{\sum_{P} m_{P}}{\sum_{j^{1}}^{N} v_{j^{1}, k}^{11} M_{j^{1}}},
\end{aligned}
$$

where $v_{i^{1}, k}^{1}$ is the stoichiometric coefficient for reactant $i^{1}$ in reaction $k, v_{j^{1}, k}^{11}$ is stoichiometric coefficient for product $j^{1}$ in reaction $k, m_{P}$ represents the mass fraction of any product species, $P, m_{R}$ represents the mass fraction of a particular reactant, $R, R$ is the reactant species giving the smallest value of $R_{i^{1}, k}, A$ and $B$ are empirical constants equal to 4.0 and 0.5 respectively. The eddy-dissipation model relates the rate of reaction to the rate of dissipation of the reactant- and product-containing eddies. $(k / \varepsilon)$ represents the time scale of the turbulent eddies following the eddy-dissipation model of Spalding (1970).

2.2c Entropy generation rate: In fluid flow, irreversibility arises due to the heat transfer and the viscous effects of the fluid. In these systems, when both temperature and velocity fields are known, the volumetric entropy generation rate $\left(S_{\mathrm{gen}}^{\prime \prime \prime}\right)$ at each point in the system can be calculated as follows (Bejan 1996a),

$$
S_{\text {gen }}^{\prime \prime \prime}=\left(S_{\text {gen }}^{\prime \prime \prime}\right)_{\text {heat }}+\left(S_{\text {gen }}^{\prime \prime \prime}\right)_{\text {fric }},
$$

where $\left(S_{\text {gen }}^{\prime \prime \prime}\right)_{\text {heat }}$ and $\left(S_{\text {gen }}^{\prime \prime \prime}\right)_{\text {fric }}$ represent the entropy generation rates due to heat transfer and fluid friction, respectively, and are defined as,

$$
\begin{aligned}
& \left(S_{\text {gen }}^{\prime \prime \prime}\right)_{\text {heat }}=\left(\lambda_{\text {eff }} / T^{2}\right) \cdot\left[(\partial T / \partial x)^{2}+(\partial T / \partial r)^{2}\right] \\
& \left(S_{\text {gen }}^{\prime \prime}\right)_{\text {fric }}=\mu_{\text {eff }} / T \cdot \Phi
\end{aligned}
$$


where $\Phi$ is

$$
\Phi=2 \cdot\left[\left(\frac{\partial u_{x}}{\partial x}\right)^{2}+\left(\frac{\partial u_{r}}{\partial r}\right)^{2}+\left(\frac{u_{r}}{r}\right)^{2}\right]+\left(\frac{\partial u_{x}}{\partial r}+\frac{\partial u_{r}}{\partial x}\right)^{2}
$$

The total entropy generation rate over the volume $\left(\dot{S}_{\text {gen }}\right)$ can be calculated as follows:

$$
\dot{S}_{\text {gen }}=\oint_{V} S_{\text {gen }}^{\prime \prime \prime} \partial \theta \cdot \partial r \cdot \partial x .
$$

Bejan number, Be, which compares the magnitude of entropy generation due to heat transfer with the magnitude of the total entropy generation, is defined by:

$$
\mathrm{Be}=\left(\dot{S}_{\text {gen }}\right)_{\text {heat }} / \dot{S}_{\text {gen }} \text {. }
$$

When $\mathrm{Be} \gg 0 \cdot 5$, irreversibility due to heat transfer dominates, while for $\mathrm{Be} \ll 0.5$ the irreversibility due to viscous effects dominates. For $\mathrm{Be} \cong 0 \cdot 5$, entropy generation due to heat transfer is almost of the same magnitude as that due to fluid friction.

Merit number $(M)$ is defined as the ratio of exergy transferred to the sum of exergy transferred and exergy destroyed (Mukherjee et al 1987), i.e.

$$
M=\dot{Q}_{a} /\left(\dot{Q}_{a}+\dot{I}\right)
$$

where $I$ is defined as,

$$
\dot{I}=T_{\mathrm{amb}} \cdot \dot{S}_{\mathrm{gen}} .
$$

$\dot{Q}_{a}$ is the rate of exergy transfer accompanying energy transfers at the rates of $\dot{Q}_{w}$ and $\dot{Q}_{\text {fluid }}$, and is given as (Mukherjee et al 1987),

$$
\begin{aligned}
\left(\dot{Q}_{a}\right)_{w} & =\dot{Q}_{w}\left[1-T_{\mathrm{amb}} /\left(T_{w}\right)_{\mathrm{awa}}\right], \\
\left(\dot{Q}_{a}\right)_{\text {fluid }} & =\dot{Q}_{\text {fluid }}\left[1-T_{\mathrm{amb}} /\left(T_{\mathrm{out}}\right)_{\mathrm{mwa}}\right],
\end{aligned}
$$

and

$$
\dot{Q}_{a}=\left(\dot{Q}_{a}\right)_{w}+\left(\dot{Q}_{a}\right)_{\text {fluid }},
$$

where $\dot{Q}_{w}$ can be written as,

$$
\dot{Q}_{w}=A_{w}\left|\left(q^{\prime \prime}\right)_{\mathrm{awa}}\right|,
$$

$\dot{Q}_{\text {fluid }}$ be written as,

$$
\dot{Q}_{\text {fluid }}=\dot{m}_{\text {fluid }}\left(C_{P}\right)_{\text {mwa }}\left|\left(T_{\text {out }}\right)_{\text {mwa }}-T_{\text {in }}\right| .
$$

The total heat transfer rate,

$$
\dot{Q}_{\text {tot }}=\dot{Q}_{w}+\dot{Q}_{\text {fluid }} .
$$


The mass-weighted average (mwa) of a quantity is computed by dividing the summation of the product of density $\left(\rho_{j}\right)$, cell volume $\left(V_{j}\right)$, and selected field variable $\left(\psi_{j}\right)$ by summation of the product of density and cell volume:

$$
(\psi)_{\mathrm{mwa}}=\sum_{j=1}^{n} \psi_{j} \cdot \rho_{j} \cdot\left|V_{j}\right| / \sum_{j=1}^{n} \rho_{j} \cdot\left|V_{j}\right| .
$$

Area-weighted average (awa) of a quantity is computed by dividing the summation of the product of the selected field variable $\left(\psi_{j}\right)$ and facet area $\left(A_{j}\right)$ by the total area of relevant surface, $(\mathrm{A})$ :

$$
(\psi)_{\mathrm{awa}}=\frac{1}{A} \sum_{j=1}^{n} \psi_{j}\left|A_{j}\right| .
$$

To obtain the total entropy generation rate, first, it is necessary to solve the governing conservation equations, given in $\S 2 \cdot 2 \mathrm{a}$, with the combustion equations given in $\S 2 \cdot 2 \mathrm{~b}$. Volumetric local entropy generation rate can be calculated by using the local velocities and temperatures obtained from the calculations of the governing conservation equations, and the total entropy generation rate over the volume can be obtained using numerical integration.

\section{Computational procedure}

\subsection{Calculational tools}

Even the difficult general differential equations are now yielding to the approximating technique known as numerical analysis, whereby the derivatives are simulated by algebraic relations between a finite number of grid points in the flow field which are then solved on a digital computer. A suitable CFD computer code can be used to solve numerically the governing equations (1)-(4) along with the thermal properties equations (5a-e), the boundary condition equations (6) and the combustion equations (7)-(9). CFD is the process by which fluid flow can be predicted through arbitrary geometries giving such information as flow speed, pressures, residence times, flow patterns etc.

FLUENT 6. 1 (Fluent Inc. 2003) was chosen as the CFD computer code for this work because of the ease with which the analysis model can be created, and because the software allows users to modify the code for special analysis conditions through the use of user subroutines. The FLUENT computer code uses a finite-volume procedure to solve the Navier-Stokes equations of fluid flow in primitive variables such as $u$-velocity, $v$-velocity, and pressure. It can also model the mixing and transport of chemical species by solving conservation equations describing convection, diffusion, and reaction sources for each component species. A variety of turbulence models is offered by the FLUENT computer code. A detailed description of turbulence models and its application to turbulence can be found in Fluent Inc. (2003). In the case of the $k-\varepsilon$ models, two additional transport equations (4a,b) with sub-equations (4c-i), (for the turbulent kinetic energy and the turbulence dissipation rate) are solved, and turbulent viscosity, $\mu_{t}$, is computed as a function of $k$ and $\varepsilon$. The RNG $k-\varepsilon$ model belongs to the $k-\varepsilon$ family of turbulence models; however, unlike the standard $k-\varepsilon$ model, the RNG $k-\varepsilon$ model was derived using a statistical technique called renormalization group methods. These model equations are similar to the standard $k-\varepsilon$ model, but the statistical derivation results in different values for the various constants in the equations. A more comprehensive description 
of RNG theory and its application to turbulence can be found in Yakhot \& Orszag (1986) and Choudhury (1993).

The RNG- $k-\varepsilon$ model was used as a turbulence model in this study. The model constants for the RNG- $k-\varepsilon$ model are $C_{\mu}=0.0845, C_{1 \varepsilon}=1.42, C_{2 \varepsilon}=1.68$, and wall Prandtl number $=0 \cdot 85$. The solution method for this study is axisymmetric. In order to achieve higher-order accuracy at cell faces, second-order upwinding is selected. In this case, quantities at cell faces are computed using a multidimensional linear reconstruction approach (Barth \& Jespersen 1989), and so higher-order accuracy is achieved at cell faces through a Taylor series expansion of the cell-centred solution about the cell centroid.

Furthermore, a computer program has been developed to calculate numerically the volumetric entropy generation rate distributions in equations (10a-d) and the other thermodynamic parameters in equations $(10 \mathrm{e}-\mathrm{j})$, by using the results of the calculations performed with the FLUENT code. This program, written in FORTRAN 77 language, calculates numerically the axial and radial derivations of the temperature $(T)$ and the components $\left(u_{x}\right.$ and $\left.u_{r}\right)$ of velocity, which are functions of the axial and radial distances, using a finite-differences approach, and thus calculates the volumetric entropy generation rate distributions, and the other thermodynamic parameters as two-dimensional. It also compares the total heat per unit mass released in the combustion with the LCV of methane which must be equal or very close to each other in the case of complete combustion.

\subsection{Simulation values}

Physical values are as follows:

$r_{f}=0.004 \mathrm{~m}, r_{i}=0.006 \mathrm{~m}, r_{o}=0.01 \mathrm{~m}, R=0.05 \mathrm{~m}, L=0.5 \mathrm{~m}, T_{\mathrm{in}}=T_{\mathrm{amb}}=T_{\mathrm{ref}}=$ $300 \mathrm{~K}, h_{\mathrm{amb}}=10 \mathrm{~W} / \mathrm{m}^{2} \mathrm{~K}, P_{\mathrm{op}}=101325 \mathrm{~Pa}$.

$\rho_{\text {air }}=1.225 \mathrm{~kg} / \mathrm{m}^{3}$ at the air inlet. Thermal properties $\left(C_{P}, \lambda\right.$ and $\left.\mu\right)$ of the methane and species are given in table 1 as functions of temperature. The density of methane at the fuel inlet and the molecular weights, enthalpies and lower heating values of reactant and product species are given in table 2 . These properties except LHV are taken from the material property database given by Fluent Inc. (2003).

3.2a Ranges of the simulation values: Simulation values are in the ranges,

$$
\begin{aligned}
\dot{Q} & =10000 \mathrm{~W}, \\
\phi & =0 \cdot 5,0 \cdot 6, \ldots, 1 \cdot 0, \\
\gamma & =10,12, \ldots, 30 \%
\end{aligned}
$$

Inlet velocities, $U_{f}$ and $U_{\text {air }}$ can be determined as follows:

$$
U_{f}=\frac{\dot{m}_{f}}{A_{f} \cdot \rho_{f}} \quad \text { and } \quad U_{\mathrm{air}}=\frac{\dot{m}_{\mathrm{air}}}{A_{\mathrm{air}} \cdot \rho_{\mathrm{air}}}
$$

where $A_{f}$ and $A_{\text {air }}$ are the areas of fuel and air inlets, respectively, and $\dot{m}_{f}$ and $\dot{m}_{\text {air }}$ are obtained from equations ( $8 \mathrm{a}-\mathrm{g}$ ) as dependent on $\gamma$ and $\phi$. Inlet velocities, $U_{f}, U_{\text {air }}$ and stoichiometric air/fuel ratios, which are determined according to $\gamma$ and $\phi$, are given in table 3 .

3.2b Grid size: Grid independent tests were carried out to ensure grid independence of the calculated results; consequently, grid size and grid orientation giving the grid independent 


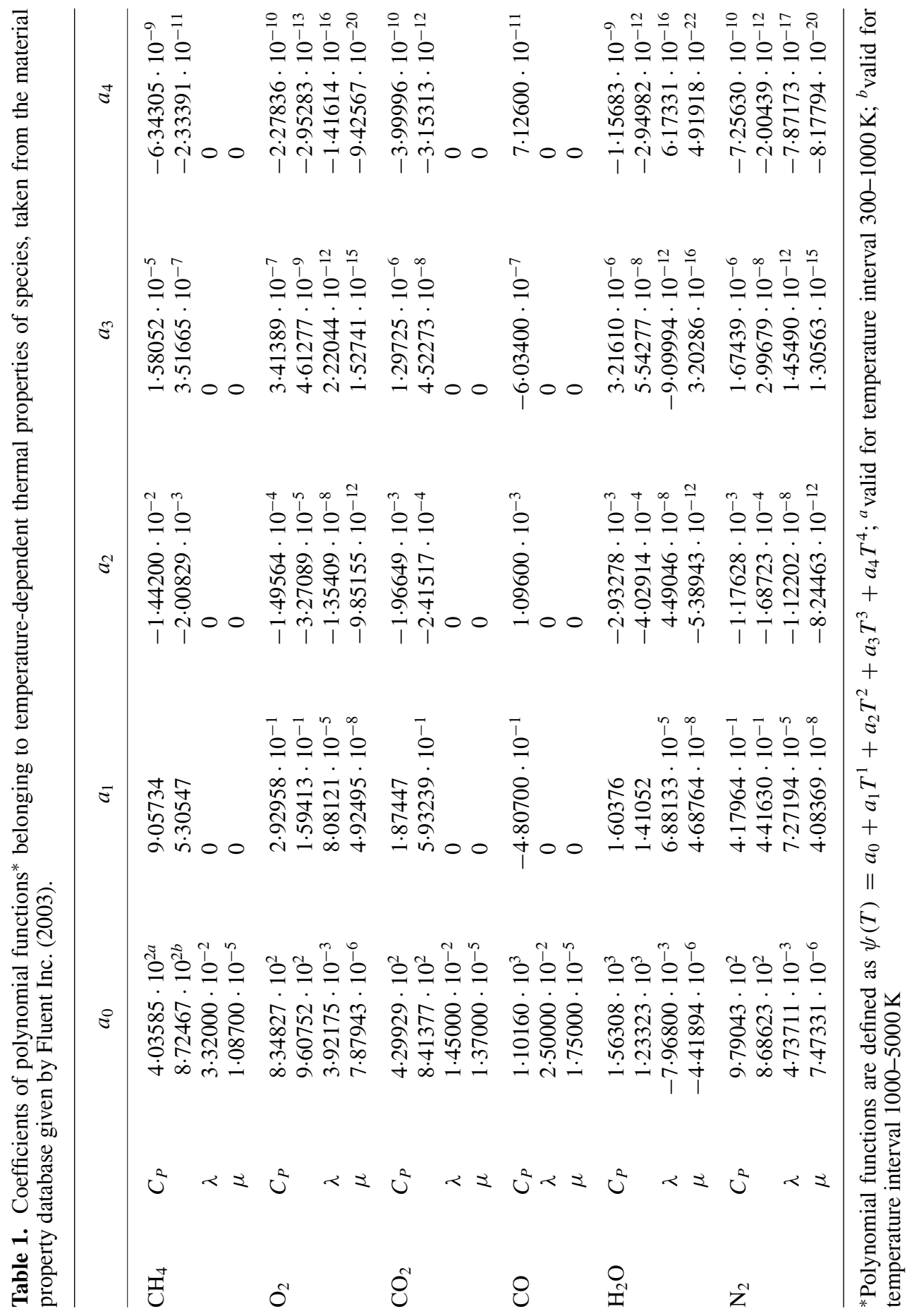


Table 2. Properties of reactant and product species.

\begin{tabular}{lcccc}
\hline Species & $\begin{array}{c}\rho^{*, a} \\
{\left[\mathrm{~kg} / \mathrm{m}^{3}\right]}\end{array}$ & $\begin{array}{c}M^{a} \\
{[\mathrm{~kg} / \mathrm{kmol}]}\end{array}$ & $\begin{array}{c}H^{a} \\
{[\mathrm{~J} / \mathrm{kmol}]}\end{array}$ & $\begin{array}{c}\text { LHV } \\
{[\mathrm{J} / \mathrm{kmol}]}\end{array}$ \\
\hline $\mathrm{CH}_{4}$ & $0 \cdot 66790$ & $16 \cdot 04303$ & $-7.48952 \cdot 10^{7}$ & $-8 \cdot 023 \cdot 10^{8}$ \\
$\mathrm{CO}_{2}$ & - & $44 \cdot 00995$ & $-3 \cdot 93532 \cdot 10^{8}$ & - \\
$\mathrm{H}_{2} \mathrm{O}$ & - & $18 \cdot 01534$ & $-2 \cdot 41838 \cdot 10^{8}$ & - \\
$\mathrm{O}_{2}$ & - & 31.99880 & - & - \\
$\mathrm{N}_{2}$ & - & $28 \cdot 01340$ & - & - \\
\hline
\end{tabular}

${ }^{*}$ At the fuel inlet; ${ }^{a}$ taken from the material property database given by Fluent Inc. (2003); ${ }^{b}$ calculated by using (8e).

results were selected, and thus a total cell number of 15000 cells $(300 \times 50$, i.e.: 250 and 50 cells at $0 \leq x \leq 0.25 \mathrm{~m}$ (dense-mesh region) and $0.25<x \leq 0.5 \mathrm{~m}$ (loose-mesh region) in the axial direction respectively, and 50 cells in the radial direction) was adopted. The grid distributions are uniform within each region. In addition to this total cell number, 100 axial lines were created to more accurately calculate the derivations of temperature and velocity components.

\section{Numerical results}

\subsection{The reaction rates}

Figures 2 and 3 show the distributions of reaction rates (the rates of reactions 1 and 2) in the combustion chamber for the cases of $\phi=0.5$ and 1.0 , respectively. Reaction rates for the oxidizations of $\mathrm{CH}_{4}$ and $\mathrm{CO}$ are given in (7a) and (7b) respectively. The effect of these reactions are apparent from these figures. With the increase of $\gamma$, these regions contract in

Table 3. Inlet velocities of air and stoichiometric air/fuel ratios.

\begin{tabular}{|c|c|c|c|c|c|c|c|}
\hline \multirow[b]{2}{*}{$\gamma[\%]$} & \multicolumn{6}{|c|}{$U$ air $[\mathrm{m} / \mathrm{s}]$} & \multirow[b]{2}{*}{$A F R_{\text {sto }}$} \\
\hline & $\phi=0.5$ & 0.6 & 0.7 & $0 \cdot 8$ & 0.9 & $1 \cdot 0$ & \\
\hline 10 & $57 \cdot 511$ & 47.926 & $41 \cdot 079$ & $35 \cdot 944$ & 31.951 & 28.756 & 35.420 \\
\hline 12 & 48.060 & 40.050 & 34.329 & $30 \cdot 038$ & $26 \cdot 700$ & 24.030 & 29.599 \\
\hline 14 & $41 \cdot 310$ & 34.425 & 29.507 & $25 \cdot 819$ & 22.950 & $20 \cdot 655$ & $25 \cdot 442$ \\
\hline 16 & $36 \cdot 247$ & $30 \cdot 206$ & $25 \cdot 891$ & $22 \cdot 654$ & $20 \cdot 137$ & $18 \cdot 123$ & $22 \cdot 324$ \\
\hline 18 & 32.309 & $26 \cdot 924$ & 23.078 & $20 \cdot 193$ & 17.950 & $16 \cdot 155$ & 19.898 \\
\hline 20 & $29 \cdot 159$ & 24.299 & $20 \cdot 828$ & $18 \cdot 224$ & 16.199 & 14.579 & 17.958 \\
\hline 22 & $26 \cdot 581$ & $22 \cdot 151$ & 18.987 & $16 \cdot 613$ & 14.767 & $13 \cdot 291$ & $16 \cdot 371$ \\
\hline 24 & 24.434 & $20 \cdot 361$ & 17.453 & $15 \cdot 271$ & $13 \cdot 574$ & $12 \cdot 217$ & $15 \cdot 048$ \\
\hline 26 & $22 \cdot 616$ & $18 \cdot 847$ & $16 \cdot 154$ & $14 \cdot 135$ & $12 \cdot 564$ & $11 \cdot 308$ & 13.929 \\
\hline 28 & 21.058 & $17 \cdot 549$ & $15 \cdot 042$ & $13 \cdot 161$ & 11.699 & $10 \cdot 529$ & 12.969 \\
\hline 30 & 19.708 & $16 \cdot 423$ & 14.077 & $12 \cdot 318$ & $10 \cdot 949$ & 9.854 & $12 \cdot 138$ \\
\hline
\end{tabular}

For $\dot{Q}=10000 W, U_{f}=5.956 \mathrm{~m} / \mathrm{s}$. 

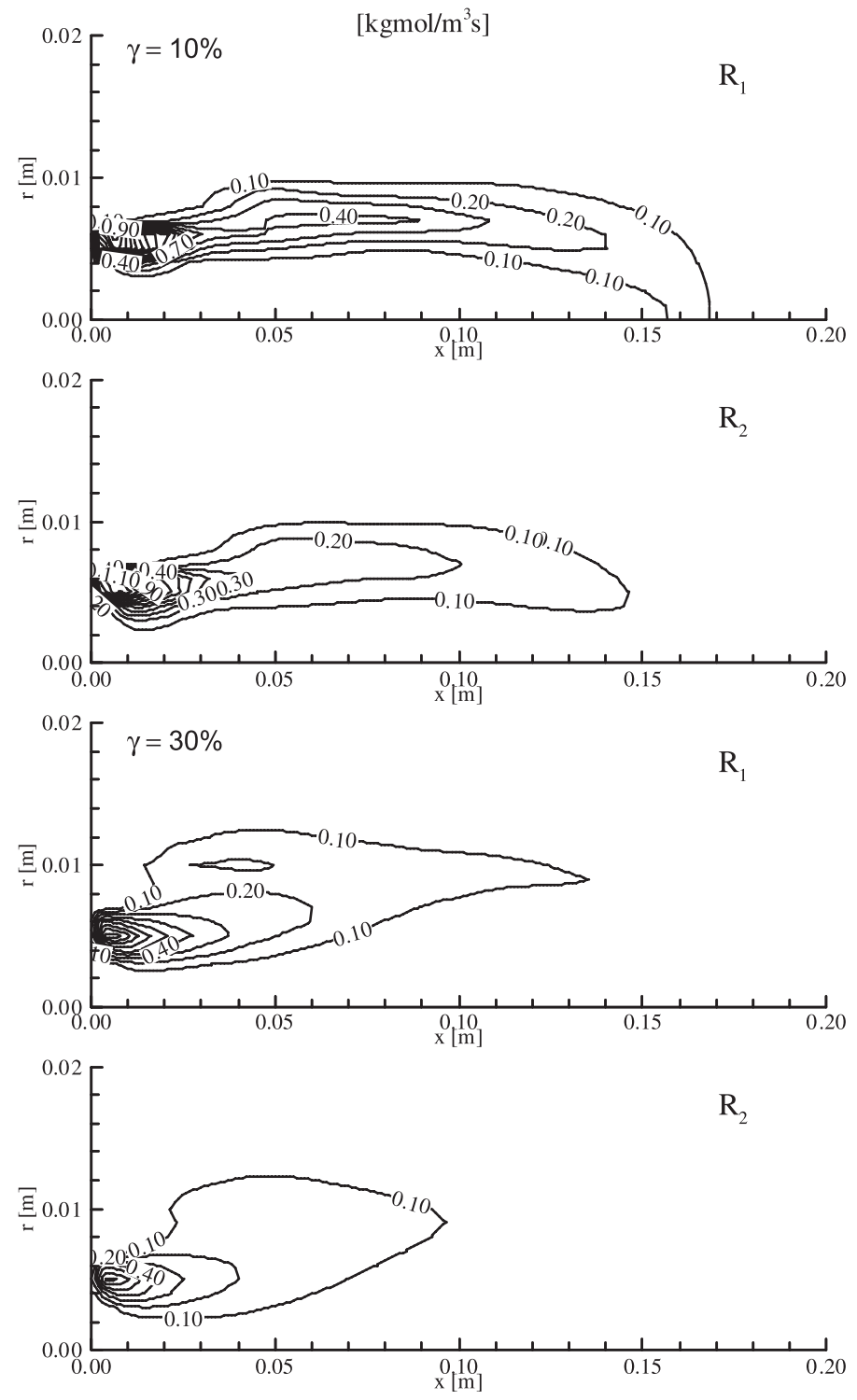

Figure 2. Contours of rates of reactions 1 and $2(\phi=0 \cdot 5)$.

the axial direction whereas they expand in the radial direction. However, the reaction rate decreases significantly with the increase of $\phi$.

The mass fraction distributions of species $\left(\mathrm{O}_{2}, \mathrm{CO}_{2}, \mathrm{CO}\right.$ and $\left.\mathrm{H}_{2} \mathrm{O}\right)$ in the combustion chamber, which are related to the distributions of reaction rates, are plotted in figures 4 $(\gamma=10 \%)$ and $5(\gamma=30 \%)$ for $\phi=0.5$ and in figures $6(\gamma=10 \%)$ and $7(\gamma=30 \%)$ for $\phi=1 \cdot 0$. The mass fraction distributions give the information about whether the complete combustion occurs. The influences of equivalence ratio and oxygen percentage in the air on the mass fraction distributions are apparent in these figures. As expected, in the case of $\phi<1$ (or the air excess ratio, $\lambda>1$ ), all methane molecules are completely burned into $\mathrm{CO}$ and 

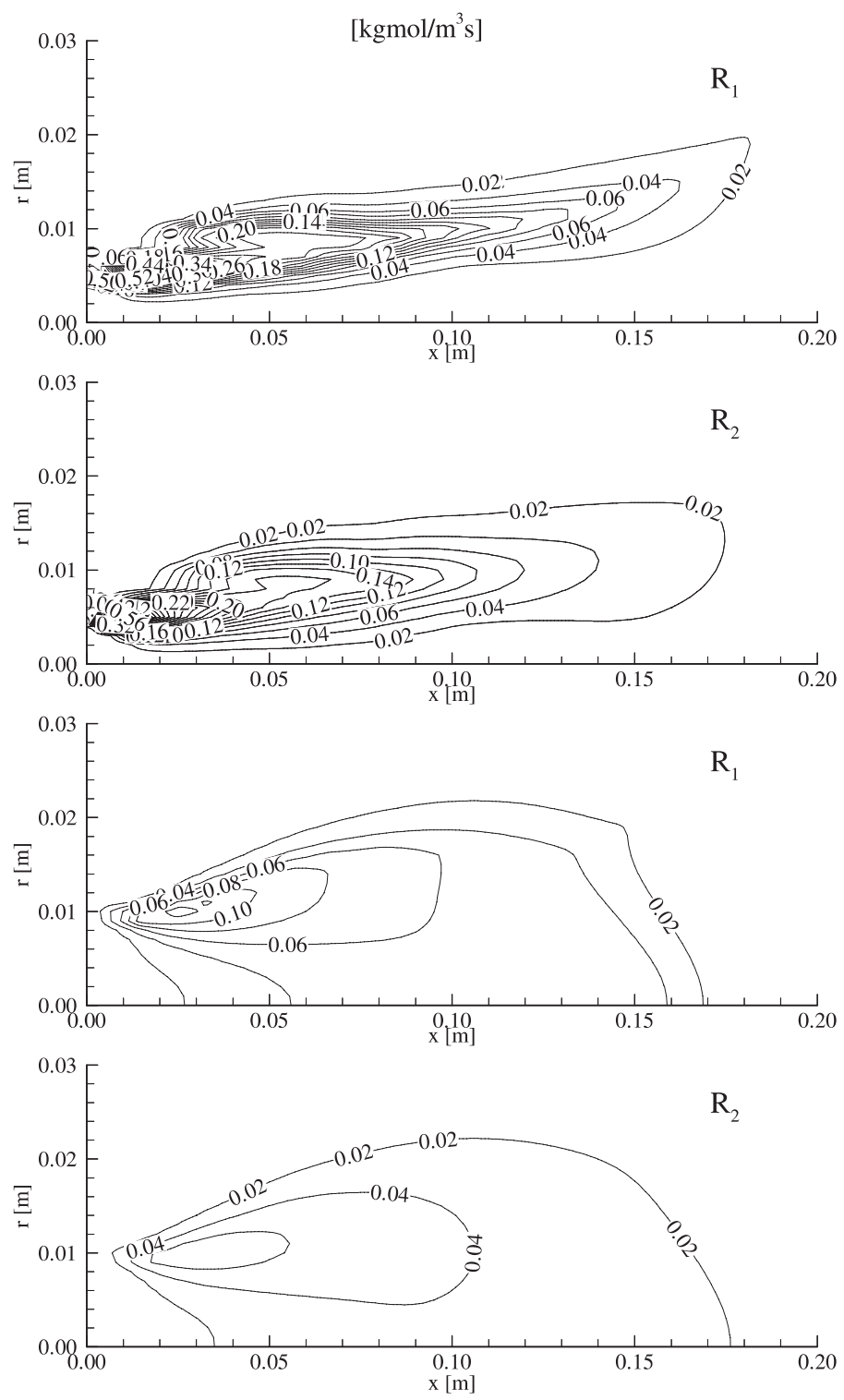

Figure 3. Contours of rates of reactions 1 and $2(\phi=1 \cdot 0)$.

$\mathrm{H}_{2} \mathrm{O}$ molecules, and the $\mathrm{CO}$ molecules are then oxidized to $\mathrm{CO}_{2}$ molecules. At the outlet; in the case of $\gamma=10 \%$, with the increase of $\phi$ (from 0.5 to 1.0 ), while the mass-weighted averages of the mass fractions of $\mathrm{CO}_{2}$ and $\mathrm{H}_{2} \mathrm{O}$, which are produced along the combustion, increase linearly from 3.95 to $6.60 \%$ and from 3.24 to $5.49 \%$ respectively, while that of $\mathrm{O}_{2}$ decreases linearly from $4.11 \%$ to 0 , and for $\gamma=30 \%$, these ranges for $\mathrm{CO}_{2}, \mathrm{H}_{2} \mathrm{O}$ and $\mathrm{O}_{2}$ ) are from 10.91 to $18.75 \%, 8.93$ to $15.71 \%$ and $12.94 \%$ to 0 respectively. The results obtained from the figures show that in the cases of $\phi<1$, complete combustion occurs, while in the case of $\phi=1$ it is very close to the complete combustion state. 

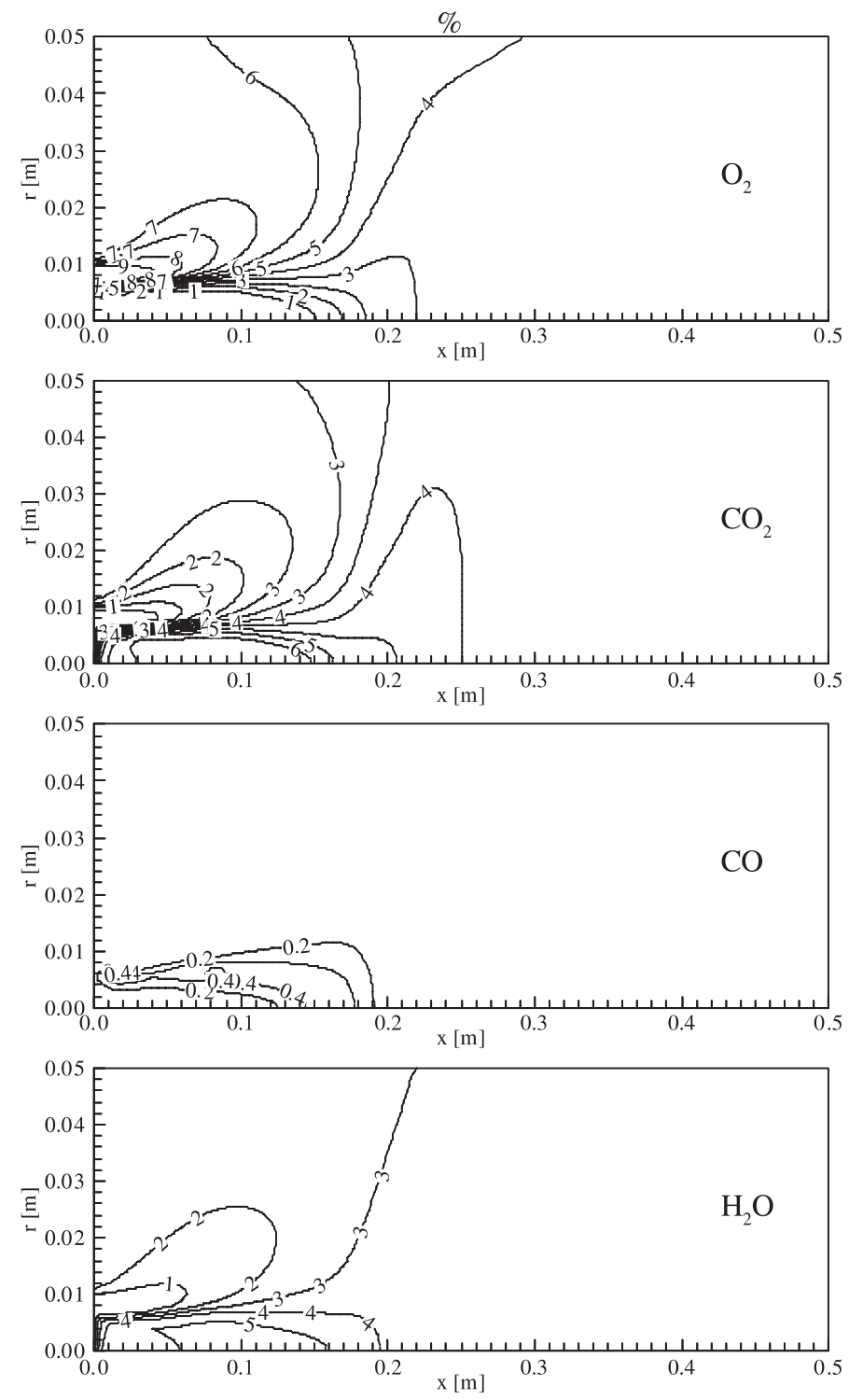

Figure 4. Mass fractions of species $(\phi=0.5$ and $\gamma=10 \%)$.

\subsection{Temperature distributions}

Heat, which is released in the chemical reaction and transferred into the flowing gas including the reactant and product molecules, increases the temperature of this gas, and hence causes the large temperature gradients that increase the local entropy generation due to the heat transfer (see (10b), in the combustion chamber. In order to view the temperature gradients in axial direction, the variations of temperature along the axis of burner are plotted in figure 8 , including two sub-graphs, depending on the axial distance. As is apparent in these sub-graphs, larger temperature gradients occur in the axial direction (especially between $x=0$ and about 

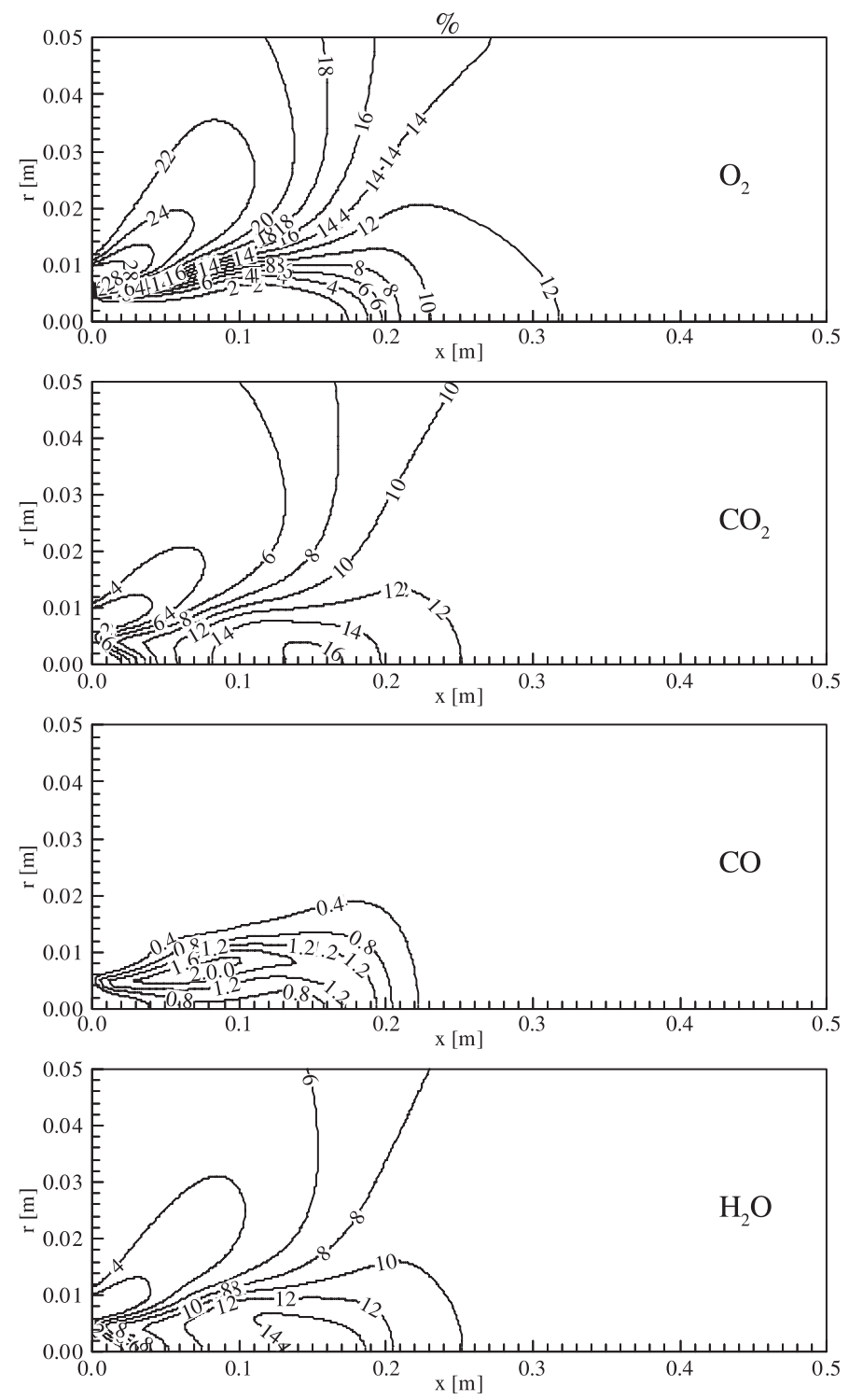

Figure 5. Mass fraction of species $(\phi=0.5$ and $\gamma=30 \%)$.

$0.20 \mathrm{~m})$. Nonetheless, the increase of $\phi$ significantly reduces the gradients. Although the increase of $\gamma$ gradually increases temperature profiles, it does not have much effect on the temperature gradient (especially after $x=0.20 \mathrm{~m}$ ).

Two-dimensional temperature distributions within the burner for the cases of $\gamma=10$ and $30 \%$ are shown in figure 9 for $\phi=0.5$ and 1.0. The influences of $\gamma$ and $\phi$ on the temperature distributions are illustrated more clearly in this figure. As expected, levels of temperature throughout the burner rises linearly with both increasing of $\gamma$ and $\phi$. The mass-weighted average temperature of the combustion chamber increases from 832 to $1384 \mathrm{~K}$ and from 1097 to $1961 \mathrm{~K}$ for the cases of $\phi=0.5$ and 1.0 respectively, with the increase of $\gamma$ from 10 to $30 \%$. 

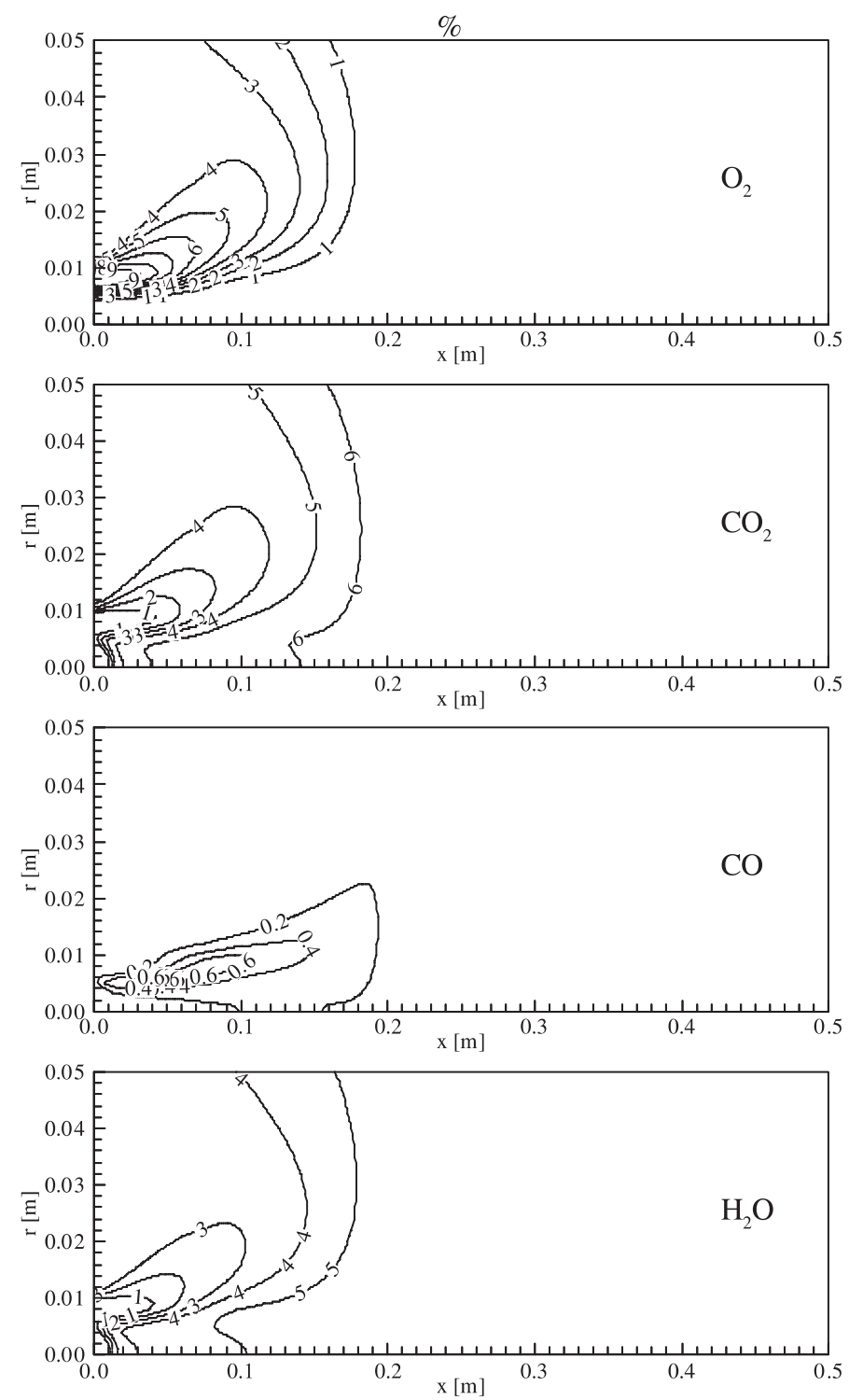

Figure 6. Mass fractions of species $(\phi=1.0$ and $\gamma=10 \%)$.

As is apparent from these results, increase in $\gamma$ affects the rise more than that in $\phi$, i.e: the average temperature increases about 70 and $35 \%$ with the increases of $\gamma$ and $\phi$ respectively.

Temperatures at the burner wall increase from 849 to $1427 \mathrm{~K}$ and from 1159 to $1962 \mathrm{~K}$ in the cases of $\phi=0.5$ and 1.0, respectively, with the increase of $\gamma$ from 10 to $30 \%$. Material resistant to high temperature must be therefore selected as the burner wall material (especially in the cases of high $\phi$ and $\gamma$ ). Furthermore, the heat transfer coefficient at the burner wall should be increased to reduce the burner wall-temperature.

The heat calculations performed for the each oxygen percentage bring out that in the case of $\phi<1$, the total heat per unit mass released in the combustion, which can be calculated 

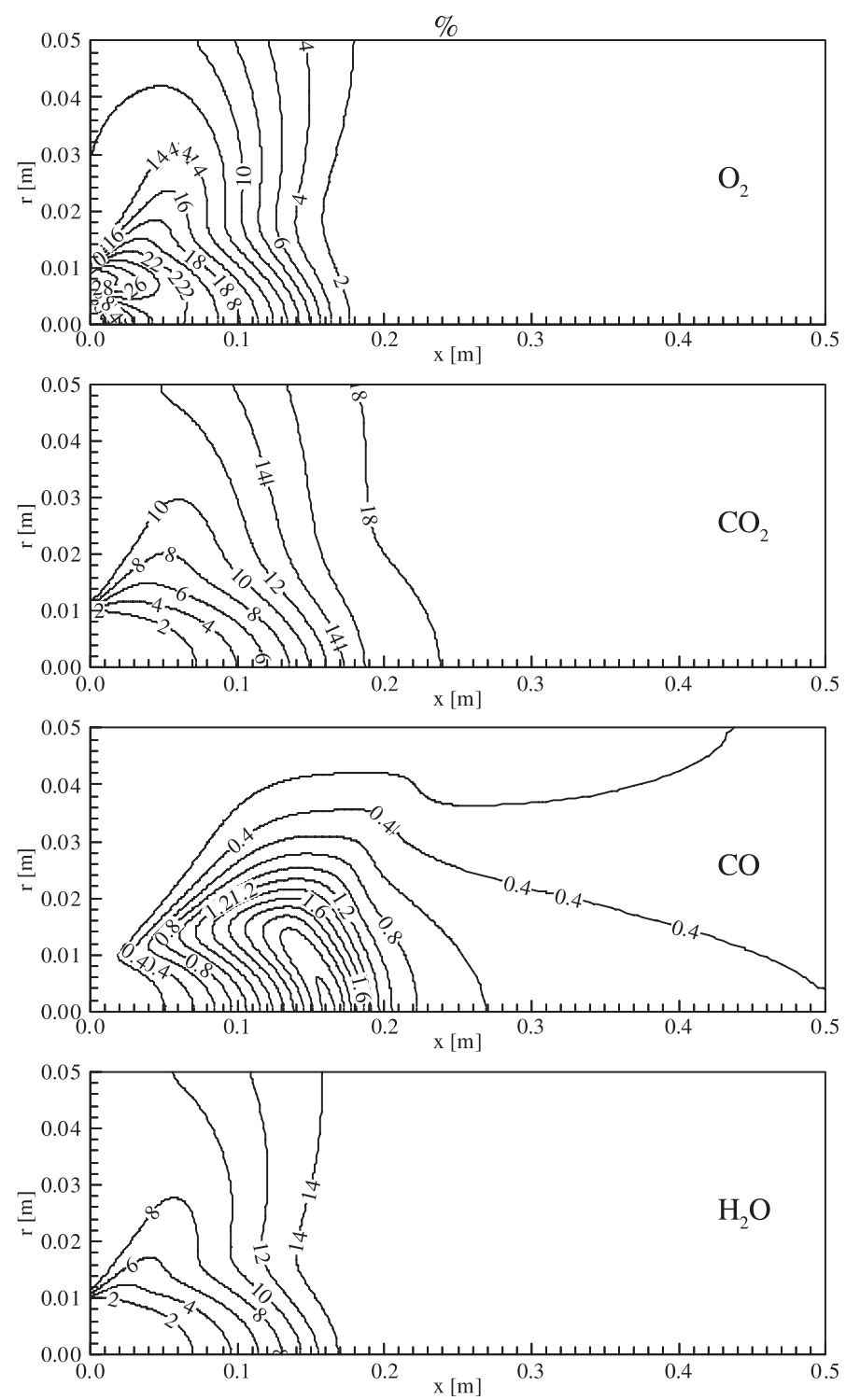

Figure 7. Mass fractions of species $(\phi=1.5$ and $\gamma=30 \%)$.

using (101-n), is almost equal to the LCV of methane and that in the case of $\phi=1$, they are very close to its LCV. Consequently, as emphasized also in $\S 4 \cdot 1$, this means that in the case of $\phi<1$, complete combustion occurs, and that in the case of $\phi=1$, it is very close to the complete combustion state.

\subsection{The local entropy generation}

The calculations bring out that in all investigated cases, the entropy generation rates due to the fluid friction are much lower with respect to those due to the heat transfer. In other 

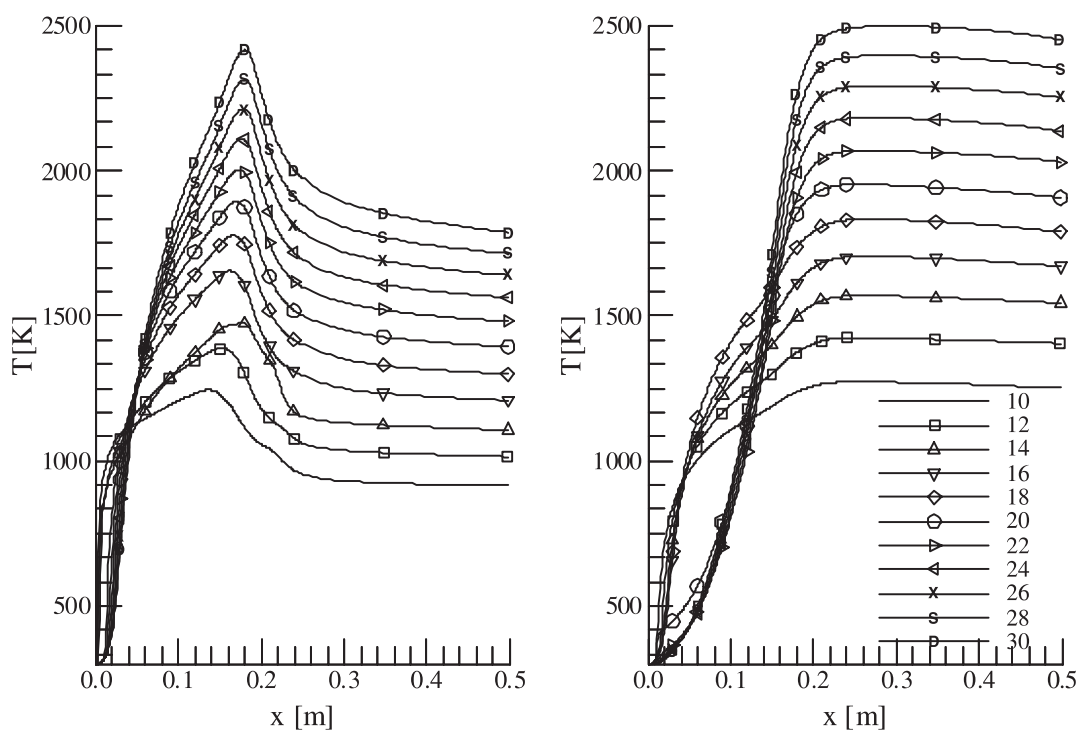

Figure 8. Variations of temperatures at the axis of burner depending on the axial distance.

words, the Bejan number, Be, is very close to 1 (about 0.996), and this, therefore, means that the irreversibility due to the heat transfer dominates. Variations of volumetric local entropy generation rates at the various radial planes in the cases of $\phi=0.5$ and 1.0 are plotted versus the axial distance in figure 10 for $\gamma=10$ and $30 \%$. Profiles showing these variations are in an irregular form due to the very large temperature gradients. However, they take shape of a quasi-smooth line towards the burner wall. In addition to this figure, the volumetric local entropy generation rate distributions within the combustion chamber for the same cases are plotted in figure 11 as the logarithmic contours. High entropy is generated in the region, in which the reaction rates are effective, and in which the large positive and negative temperature gradients occur in the axial and radial directions. The maximum values of volumetric local entropy generation rates vary in the range of $602560 \mathrm{~W} / \mathrm{m}^{3} \mathrm{~K}(5.78$ as the logarithmic) to $2951209 \mathrm{~W} / \mathrm{m}^{3} \mathrm{~K}(6.47$ as the logarithmic $)$ depending $\phi$ and $\gamma$. It is apparent from these figures that the variations of $\phi$ and $\gamma$ have an irregular effect on the volumetric local entropy generation rate distribution. These values bring out that the volumetric local entropy generation rates decrease about 9 and $4 \%$ in the cases of $\phi=0.5$ and 1.0 respectively, with an increase of $\gamma$ from 10 to $30 \%$.

Figure 12 shows the variations of entropy generation rates over the volume and merit numbers, which represent the maximum heat transfer rate to sum of the maximum heat transfer rate and the total irreversibility, with the oxygen percentage in all considered cases. On the contrary of the volumetric local entropy generation rate profiles, these total entropy generation rate profiles have a quasi-regular form and decrease exponentially with both increases of $\phi$ and $\gamma$. In the cases of $\phi=0.5$ and 1.0 , they decrease from 17.55 to $5.00 \mathrm{~W} / \mathrm{K}$ and from 5.56 to $1.95 \mathrm{~W} / \mathrm{K}$ respectively, with increase of $\gamma$ from 10 to $30 \%$. It is apparent from these results that increase of $\phi$ reduces the amount of decrease in the total entropy generation rate.

Merit number profiles in the same cases of $\phi$ exhibit a situation contrary mentioned in the previous paragraph, i.e.: in the cases of $\phi=0.5$ and 1.0 , they increase from 0.56 to 0.85 

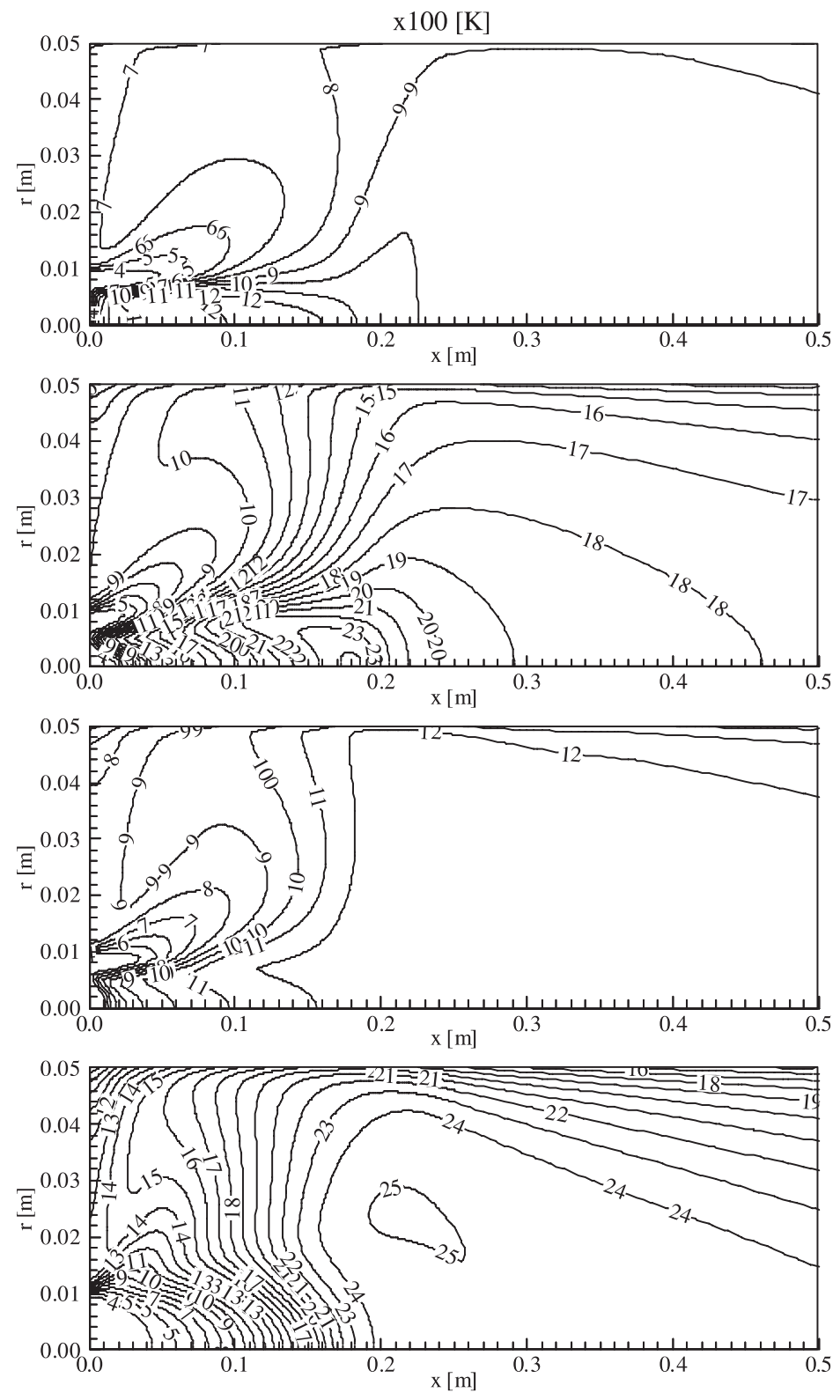

Figure 9. Temperature contours.

and from 0.80 to 0.93 , respectively, with the increase of $\gamma$ from 10 to $30 \%$. The increase of $\phi$ reduces also the amount of increase in the merit number. These values indicate that the useful energy transfer rate to irreversibility rate improves as the oxygen percentage increases. Consequently, the case of $\phi=1.0$ and $\gamma=30 \%$ is the most suitable case in terms of the entropy generation. 

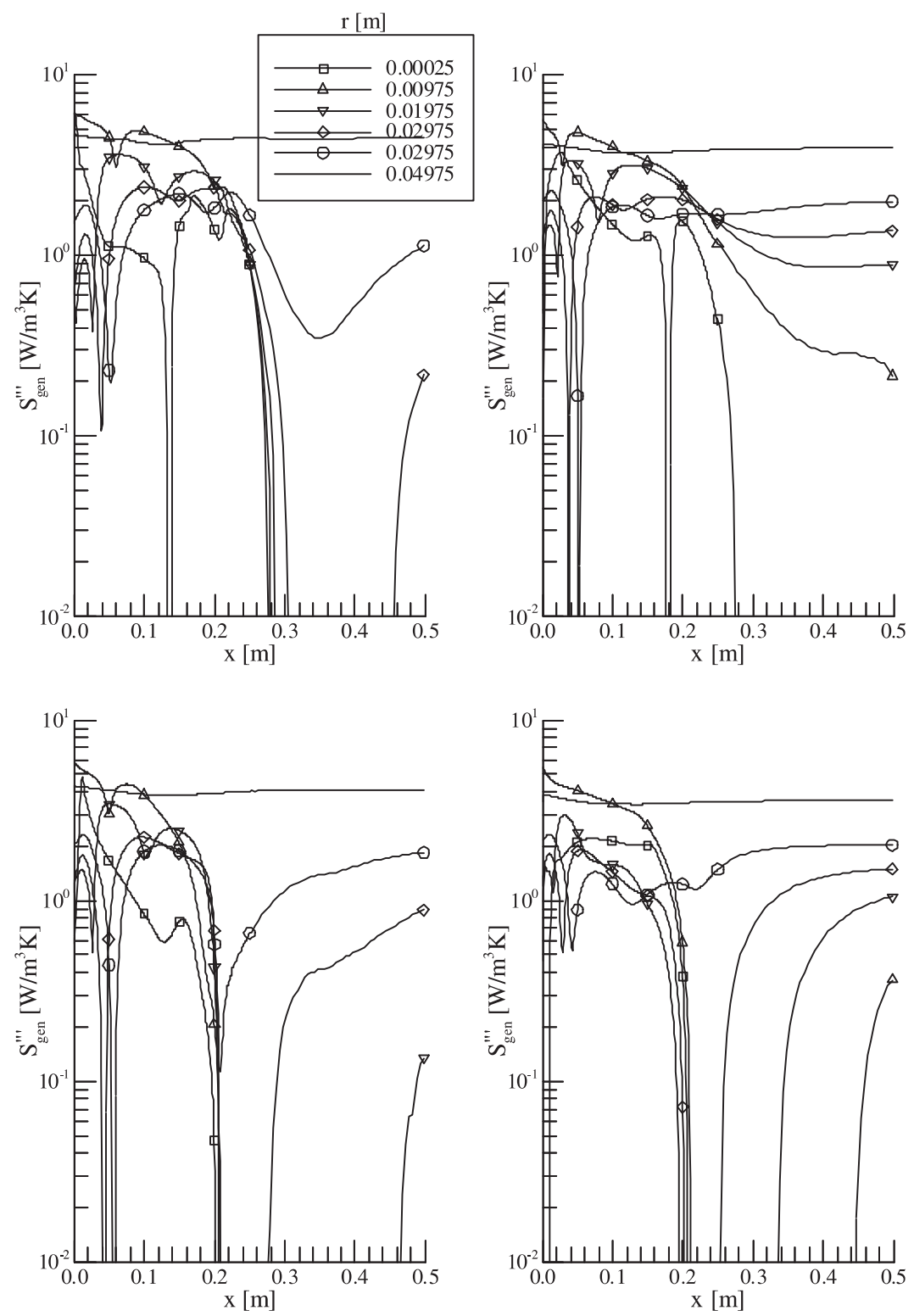

Figure 10. Variations of volumetric local entropy generation rates at various radial planes depending on the axial distance.

\section{Conclusions}

The combustion of methane with air in a burner was considered to determine numerically the local entropy generation rate in the combustion chamber. The effects of the equivalence ratio and oxygen percentage in the air on the combustion and entropy generation rate also were investigated. The resulting local entropy generation rates due to heat transfer and fluid 

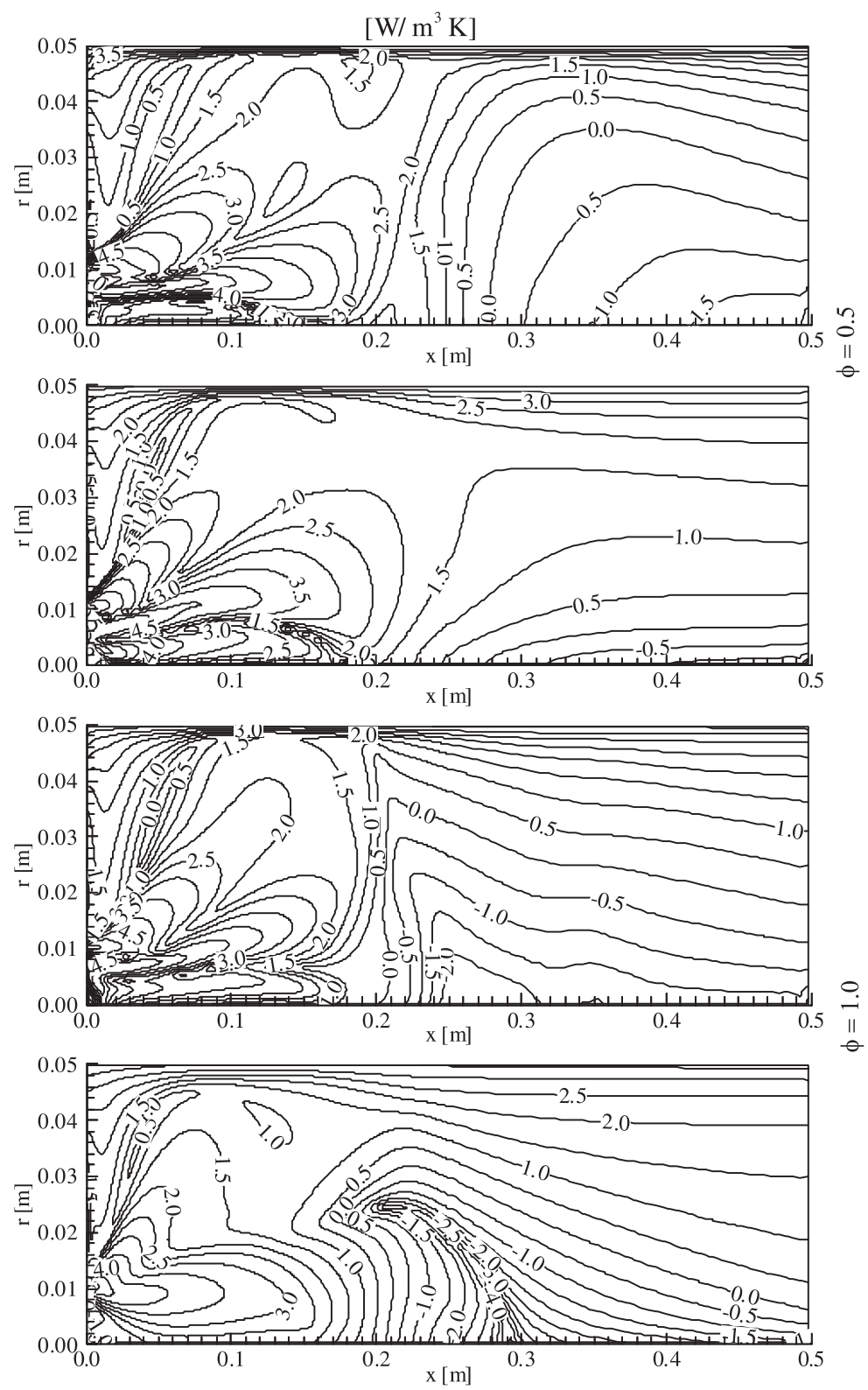

Figure 11. Logarithmic volumetric local entropy generation rate contours.

friction contributions were computed. The specific conclusions derived from this study can be listed briefly as follows.

- The increase of $\phi$ reduces significantly the reaction rate levels

- The mass-weighted averages of the mass fractions of $\mathrm{CO}_{2}$ and $\mathrm{H}_{2} \mathrm{O}$ increase linearly with both increases of $\phi$ and $\gamma$ 


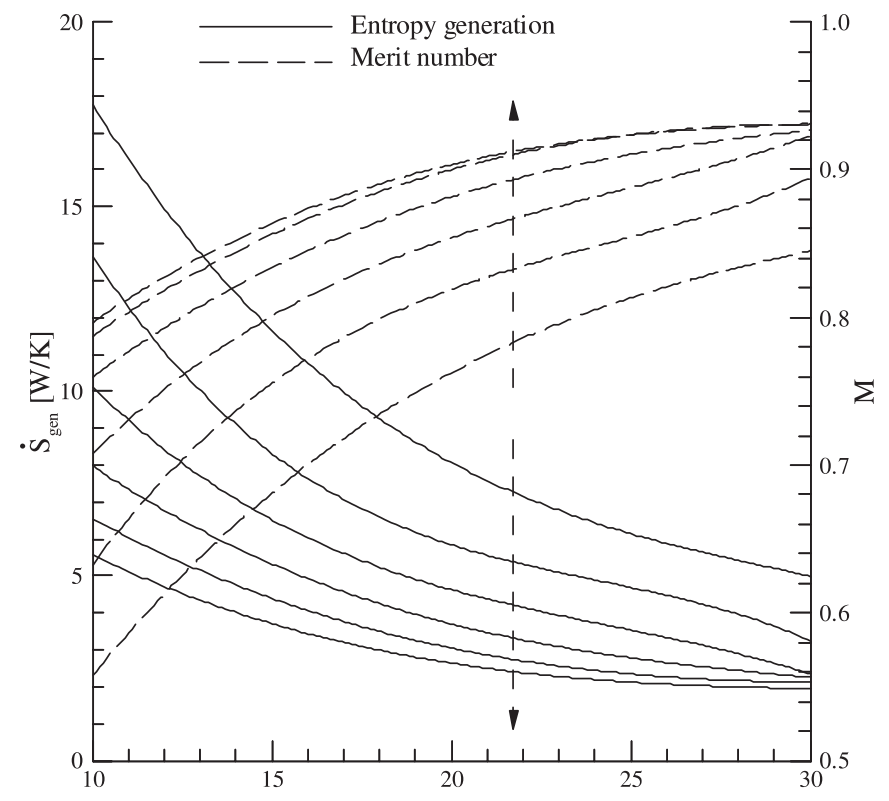

Figure 12. Variations of entropy generation rates over the volume and merit numbers versus the oxygen percentage in the air.

- The average temperatures in the combustion chamber increase about 70 and $35 \%$ with the increases of $\gamma$ (from 10 to $30 \%$ ) and $\phi$ (from 0.5 to $1 \cdot 0$ ), respectively

- In the case of $\phi<1$, the complete combustion occurs, and the combustion in the case of $\phi=1$ is very close to the complete combustion state

- In all investigated cases, the Bejan number is very close to 1 (about 0.996). Therefore, the irreversibility due to the heat transfer dominates

- The volumetric local entropy generation rates decrease about 9 and $4 \%$ in the cases of $\phi=0.5$ and 1.0 , respectively, with the increase of $\gamma$ from 10 to $30 \%$

- The total entropy generation rates decrease exponentially with increase of both $\phi$ and $\gamma$

- The merit numbers increase with increase of both $\phi$ and $\gamma$. The useful energy transfer rate to irreversibility rate therefore improves as the oxygen percentage increases.

Consequently, the results of this study clearly demonstrate the numerical simulation of combustion of methane with air and the numerical solution of local entropy generation rate in the combustion chamber for various equivalence ratios and oxygen percentages in the air. Material resistant to high temperatures must be selected as the burner wall-material (especially in the cases of high $\phi$ and $\gamma$ ), and in order to reduce the burner-wall temperature, the heat transfer coefficient at the burner wall should be increased.

\section{List of symbols}
$A$
area;
A empirical constant (4.0);
$A F R \quad$ air/fuel ratio;
$B \quad$ empirical constant (0.5);
Be Bejan number; 
$C_{\mu}, C_{1 \varepsilon}, C_{2 \varepsilon} \quad$ coefficients in $k-\varepsilon$ turbulence model;

$C F D \quad$ computational fluid dynamics;

$C_{P} \quad$ specific heat;

D mass diffusion coefficient;

E energy;

$G_{k} \quad$ the production of turbulent kinetic energy;

$h \quad$ heat transfer coefficient, sensible enthalpy;

$H \quad$ enthalpy of species;

I irreversibility rate;

J mass diffusion;

$k \quad$ turbulent kinetic energy;

$L \quad$ length of burner;

LCV lower calorific value;

LHV lower heating value;

$m$ mass;

$m \quad$ mass fraction of species;

$\dot{m} \quad$ mass flow rate;

$M \quad$ merit number, molecular weight of species;

$N \quad$ total number of species number;

$N_{R} \quad$ reaction number;

$P \quad$ pressure;

$q^{\prime \prime} \quad$ heat flux per unit area;

$\dot{Q} \quad$ heat transfer rate;

$\dot{Q}_{a} \quad$ exergy transfer rate;

$r \quad$ radial distance;

$r_{i} \quad$ inner radius of air inlet;

$r_{o} \quad$ outer radius of air inlet;

$R \quad$ radius of burner;

$R_{i^{1}} \quad$ mass rate of creation or depletion by chemical reaction;

$R_{i^{1}, k} \quad$ reaction rate;

$\Re \quad$ universal gas constant;

RNG renormalization group;

$S \quad$ modulus of the mean rate-of-strain tensor;

$S_{i j} \quad$ mean strain rate;

Sc Schmidt number;

$S_{\text {gen }}^{\prime \prime \prime} \quad$ volumetric entropy generation rate;

$\dot{S}_{\text {gen }}$

$S_{h}$

$T$

$u$

$U$

$v^{1}$

$v^{11}$

V

$x$

$X$

integrated entropy generation rate;

source term;

temperature;

velocity;

axial inlet velocity;

stoichiometric coefficient for reactant;

stoichiometric coefficient for product;

volume;

axial distance;

mole fraction of species; 
Greek symbols

$\alpha \quad$ inverse effective Prandtl number;

$\beta \quad$ model constant;

$\gamma \quad$ oxygen percentage in air;

$\chi \quad$ additional term in the $\varepsilon$ equation;

$\delta_{i j} \quad$ Kronecker delta;

$\varepsilon \quad$ turbulent energy dissipation rate;

$\phi \quad$ equivalence ratio;

$\eta_{0} \quad$ model constant;

$\Phi \quad$ viscous dissipation;

$\lambda \quad$ thermal conductivity;

$\lambda \quad$ air excess ratio;

$\mu \quad$ dynamic viscosity;

$\theta \quad$ tangential direction;

$\rho$ density;

$\tau \quad$ stress tensor;

$\psi \quad$ arbitrary variable;

Subscripts

act actual;

air air;

amb ambient;

awa area-weighted average;

eff effective;

$f \quad$ fuel;

fluid fluid;

fric friction;

heat heat transfer;

$i, j \quad$ indices of tensor notation;

$i^{1}, j^{1} \quad$ species number;

in inlet;

$j \quad$ cell number;

$k \quad$ reaction number;

max maximum;

mwa mass-weighted average;

op operation condition;

out out;

$P \quad$ product species number;

$R \quad$ reactant species number;

ref reference;

$r$ radial;

sto stoichiometric;

$t \quad$ turbulent;

tot total;

$w \quad$ wall;

$x \quad$ axial. 


\section{References}

Abbassi H, Magherbi M, Brahim A B 2003 Entropy generation in Poiseuille-Benard channel flow. Int. J. Thermal Sci. 42: 1081-1088

Barth T J, Jespersen D 1989 The design and application of upwind schemes on unstructured meshes. AIAA 27th Aerospace Sciences Meeting, Reno, (Nevada) Technical Report AIAA-89-0366

Bejan A 1996a Entropy generation minimization (Boca Raton, NY: CRC)

Bejan A 1996b Entropy minimization: the new thermodynamics of finite-size devices and finite-time processes. J. Appl. Phys. 79: 1191-1218

Choudhury D 1993 Introduction to the renormalization group method and turbulence modeling. Fluent Inc. Tech. Memo. TM-107

Demirel Y, Kahraman R 1999 Entropy generation in a rectangular packed duct with wall heat flux. Int. J. Heat Mass Transfer 42: 2337-2344

Fluent Inc. 2003 FLUENT 6.1 User's guide. (Lebonon, NH: Fluent Inc.)

Magnussen B F, Hjertager B H 1976 On mathematical models of turbulent combustion with special emphasis on soot formation and combustion. In 16th Int. Symposium on Combustion (Philadelphia, PA: The Combustion Institute)

Mahmud S, Fraser R A 2003 The second law analysis in fundamental convective heat transfer problems. Int. J. Thermal Sci. 42: 177-186

Mahmud S, Fraser R A 2002 Thermodynamic analysis of flow and heat transfer inside channel with two parallel plates. Exergy, Int. J. 2: 140-146

Mukherjee P, Biswas G, Nag P K 1987 Second-law analysis of heat transfer in swirling flow through a cylindrical duct. ASME J. Heat Transfer 109: 308-13

Sahin A Z 1998a Second law analysis of laminar viscous flow through a duct subjected to constant wall temperature. ASME J. Heat Transfer 120: 76-83

Sahin A Z 1998b A second law comparison for optimum shape of duct subjected to constant wall temperature and laminar flow. Heat Mass Transfer 33: 425-430

Sahin A Z 1999 Effect of variable viscosity on the entropy generation and pumping power in a laminar fluid flow through a duct subjected to constant heat flux. Heat Mass Transfer 35: 499-506

Sahin A Z 2000 Entropy generation in turbulent liquid flow through a smooth duct subjected to constant wall temperature. Int. J. Heat Mass Transfer. 43: 1469-1478

Sahin A Z 2002 Entropy generation and pumping power in a turbulent fluid flow through a smooth pipe subjected to constant heat flux. Exergy, Int. J.. 2: 314-321

Shuja S Z, Yilbas B S 2001 A laminar swirling jet impingement on to an adiabatic wall. Effect of inlet velocity profiles. Int. J. Numer. Methods Heat Fluid Flow 11: 237-254

Shuja S Z, Yilbas B S, Iqbal M O, Budair M O 2001a Flow through a protruding bluff body - heat and irreversibility analysis. Exergy, Int. J. 1: 209-215

Shuja S Z, Yilbas B S, Budair M O 2001b Local entropy generation in an impinging jet: minimum entropy concept evaluating various turbulence models. Comput. Methods Appl. Mech. Eng. 190: 3623-3644

Shuja S Z, Yilbas B S, Rashid M 2003 Confined swirling jet impingement onto an adiabatic wall. Int. J. Heat Mass Transfer 46: 2947-2955

Spalding D B 1970 Mixing and chemical reaction in steady confined turbulent flames. In 13th Int. Symposium on Combustion (Philadelphia, PA: The Combustion Institute)

Yakhot V, Orszag S A 1986 Renormalization group analysis of turbulence: I. Basic theory. J. Sci. Comput. 1: 1-51

Yilbas B S, Shuja S Z, Budair M O 1999 Second law analysis of a swirling flow in a circular duct with restriction. Int. J. Heat Mass Transfer 42: 4027-4041 